\title{
Management and Outcome of Ectopic Pregnancy in a Tertiary Care Center
}

\author{
${ }^{1}$ T Alpana, ${ }^{2} \mathrm{R}$ Nagarathnamma, ${ }^{3}$ Nagendra Prasad
}

\section{ABSTRACT}

Objective: To assess the results of management of ectopic pregnancy with respect to maternal morbidity and mortality and to analyze the risk factors.

Materials and methods: Hospital based cross-sectional study of 52 patients who were diagnosed as ectopic pregnancy in the reproductive age group of 15 to 44 years.

Results: A total of 62 patients with ectopic pregnancy were identified and studied. The rate of ectopic pregnancy was 1.26:100 deliveries. The mean age was found to be 26 years and majority of them were multigravida (Tables 1 and 2). The most common presenting symptom was abdominal pain $(96.15 \%)$ (Table 3$)$. Most patients had tubal ectopic pregnancy $(94.2 \%)$. Ovarian ectopic occurred in two cases and 1 patient had heterotopic pregnancy. Emergency laparotomy was performed in $39(62.90 \%)$ patients, $3(5.77 \%)$ patients received methotrexate injection while $18(29.0 \%)$ patients were managed by operative laparoscopy (Table 5). All cases of laparotomy did not require any further procedure. Out of three cases, 2 $(66.66 \%)$ cases of medical treatment were successful while only $1(33.33 \%)$ case proceeded to emergency laparotomy. No maternal death occurred. Intensive care unit (ICU) stay was needed in 5 patients. Risk factors were found in $67.3 \%$ and most common risk factor was found to be previous pelvic surgeries $(56.45 \%)$ (Table 6$)$. Heterotopic pregnancy was managed by expectant method. Two patients were of post-intrauterine contraceptive device.

Conclusion: Although there was no mortality in our study, morbidity was significant which required multiple blood transfusion and ICU admission. High degree of suspicion, early diagnosis using hormonal studies, sonography, and management in an institutional set up can reduce the associated morbidity.

Keywords: Ectopic pregnancy, Laparoscopy, Laparotomy, Methotrexate.

How to cite this article: Alpana T, Nagarathnamma R, Prasad N. Management and Outcome of Ectopic Pregnancy in a Tertiary Care Center. J Med Sci 2016;2(3):45-47.

Source of support: Nil

Conflict of interest: None

\footnotetext{
${ }^{1}$ Postgraduate, ${ }^{2}$ Professor and Head, ${ }^{3}$ Professor

${ }^{1-3}$ Department of Obstetrics and Gynecology, RajaRajeswari Medical College \& Hospital, Bengaluru, Karnataka, India

Corresponding Author: TAlpana, Postgraduate, Department of Obstetrics and Gynecology, RajaRajeswari Medical College and Hospital, Bengaluru, Karnataka, India, e-mail: alpana10april@ gmail.com
}

\section{INTRODUCTION}

Following fertilization, normally blastocyst implants in the endometrial lining of uterine cavity, implantation elsewhere is considered ectopic pregnancy. Ectopic pregnancy accounts for approximately $2 \%$ of all recognized pregnancies. ${ }^{1}$ The mean annual rate of ectopic pregnancy is $0.64 \%$ in patients of age 15 to 44 years and the incidence is increased from 0.5 to 2 per 100 pregnancies in the past 30 years. $^{2}$

The management of ectopic pregnancy has undergone a sea change. This has resulted in several nonsurgical options instead of solely surgically treatable condition. Transvaginal ultrasound and quantitative $\beta$-hCG estimation help in early diagnosis. This minimizes the morbidity, mortality, and financial burden created by this condition. ${ }^{3,4}$ Medical management has an established role in the treatment of ectopic pregnancy, ${ }^{5,6}$ but not much data are available so far.

\section{AIM}

Study was done to analyze the risk factors and assess the results of management with respect to the maternal morbidity and mortality of ectopic pregnancy.

\section{MATERIALS AND METHODS}

- Study subjects: All patients who are diagnosed as ectopic pregnancy in reproductive age group of 15 to 44 years.

- Diagnosed after a clinical examination and investigations.

- Study period: From 10/01/2013 to 09/30/2015.

- Study design: Hospital based, cross-sectional study.

- Patients diagnosed of ectopic pregnancy based on history, examination, and investigations. They were treated by one of the four treatment modalities. Informed consent was taken and data were recorded. As per the inclusion criteria, patients presenting with hemodynamic shock, having $\beta$-hCG levels $>2000 \mathrm{mIU} / \mathrm{mL}$, or those suspected to have ruptured tubal pregnancies were treated with immediate laparotomy. Patients with intact tubal pregnancy, who were hemodynamically stable, with a mass size $<6 \mathrm{~cm}$ or contraindication to methotrexate were to be planned for laparoscopy. Contraindications include 
leukopenia, thrombocytopenia, or elevated serum liver enzymes or creatinine.

Inclusion criteria for expectant management to patients with tubal ectopic pregnancies only, decreasing serial $\beta$-hCG levels, diameter of the ectopic mass $\leq 2 \mathrm{~cm}$, and no evidence of intra-abdominal bleeding or rupture by transvaginal sonography. Patients who were minimally symptomatic with $\beta$-hCG $<3000 \mathrm{mIU} / \mathrm{mL}$, pregnancy diameter $<4 \mathrm{~cm}$, nonviable pregnancy, and no signs of rupture were treated with methotrexate injection in a dose of $1 \mathrm{mg} / \mathrm{kg}$ body weight. In patients with more than 10 to $15 \%$ fall of $\beta$-hCG level did not occur in 48 hours or size of the mass further increased after 7 days, a second dose of intramuscular injection of methotrexate was administered.

\section{RESULTS AND ANALYSIS}

- Number of cases: 62 patients

- Incidence: 12.6 per 1000 deliveries.

A total of 62 patients with ectopic pregnancy were identified and studied. The rate of ectopic pregnancy was 1.26:100 deliveries. The mean age was found to be 26 years and majority of them were multigravida (Tables 1 and 2). The most common presenting symptom was abdominal pain (80.6\%) (Table 3). 57 patients had tubal ectopic pregnancy $(91.9 \%)$. Ovarian ectopic occurred in 4 cases, and 1 patient had heterotopic pregnancy (Table 4 ).

Emergency laparotomy was performed in $39(65.38 \%)$ patients, $3(5.77 \%)$ patients received methotrexate injection while $18(25 \%)$ patients were managed by operative laparoscopy (Table 5). All cases of laparotomy did

Table 1: Age distribution

\begin{tabular}{cll}
\hline Age & No. of patients & Percentage \\
\hline$<20$ & 9 & 17.30 \\
$21-25$ & 19 & 36.54 \\
$26-30$ & 27 & 43.54 \\
$31-35$ & 6 & 11.54 \\
$>35$ & 1 & 1.92 \\
\hline
\end{tabular}

Average of 26 years

Table 3: Symptoms

\begin{tabular}{lllll}
\hline & & Bleeding & & All \\
& Pain abdomen & $p / v$ & Amenorrhea & three \\
\hline No. of patients & 50 & 27 & 37 & 23 \\
\hline
\end{tabular}

Table 5: Mode of treatment

\begin{tabular}{lll}
\hline Mode of treatment & No. of patients & Percentage \\
\hline Laparotomy & 39 & 62.90 \\
Laparoscopy & 18 & 29.00 \\
Methotrexate & 3 & 5.77 \\
Failed medical management & 1 & 1.92 \\
Expectant management & 1 & 1.92 \\
\hline
\end{tabular}

not require any further procedure. Out of three cases, $2(66.66 \%)$ cases of medical treatment were successful while only $1(33.33 \%)$ case proceeded to emergency laparotomy. No maternal death occurred. Intensive care unit stay was needed for 5 patients. Risk factors were found in $67.3 \%$ and most common risk factor was found to be previous pelvic surgeries (56.45\%) (Table 6).

\section{Blood Loss and Blood Transfusion}

- Average of $405 \mathrm{~mL}$

- Maximum was $2800 \mathrm{~mL}$-Left cornual rupture

- Around 27 out of 52 required blood transfusion.

\section{DISCUSSION}

As per the history, first attempts to diagnose ectopic pregnancy started from the beginning of the 20th century. The first diagnostic tool was initially laparotomy and later diagnostic laparoscopy. With the advent of laparoscopy, it became easier to make the diagnosis. From 1970, a nonsurgical diagnostic strategy for ectopic pregnancies was developed using a combination of ultrasonography and serum hCG estimations. Later, innovations of these diagnostic methods have led to diagnosis of ectopic pregnancy into multiple types depending on their appearance on ultrasonography which include viable ectopic pregnancy, ectopic mass, and pregnancy of unknown location. Modalities of treatment in the beginning of the twentieth century were salpingectomy by laparotomy. Later in the 70s, laparoscopy was used for surgical treatment, either by salpingectomy or by salpingotomy.

Table 2: Gravida

\begin{tabular}{lll}
\hline Gravida & No. of patients & Percentage \\
\hline Primigravida & 18 & 25.00 \\
Multigravida & 40 & 67.31 \\
Grand multigravida $(>4)$ & 4 & 7.69 \\
\hline
\end{tabular}

Table 4: Site of ectopic

\begin{tabular}{llll}
\hline & No. of cases & Right side & Left side \\
\hline Tubal & 57 & 28 & 29 \\
Ovarian & 4 & 2 & 2 \\
Heterotopic & 1 & 1 & 0 \\
\hline
\end{tabular}

Table 6: Risk factors

\begin{tabular}{ll}
\hline Risk factors & No. of cases (\%) \\
\hline History dilatation and curettage & $7(11.29)$ \\
History pelvic inflammatory disease & $5(8.06)$ \\
History pelvic surgery & $35(56.45)$ \\
History previous ectopic & $3(4.83)$ \\
History infertility & $10(16.12)$ \\
History IUCD & $2(3.22)(1$ IUCD in situ) \\
\hline Total & 62 \\
\hline
\end{tabular}


Systemic methotrexate is used in the medical management option in patients with ectopic pregnancy and without active bleeding presenting with low-initial serum hCG concentrations. The expectant management may be considered in patiens with low and plateauing serum hCG. The severity of ectopic pregnancies has not changed, but the tools to diagnose ectopic pregnancy have enabled earlier diagnosis and treatment. ${ }^{7}$

The average incidence of ectopic in our study is comparable with the study by Mahboob et al. ${ }^{8}$

Laparoscopy is used in the management of ectopic pregnancy which was evident in our study also. ${ }^{4}$ Laparoscopic surgery has been compared with the open surgery in 228 patients in three randomized controlled trials. Laparoscopic procedures were associated with the shorter operation time, less intraoperative blood loss, shorter hospital stay, and lesser analgesic requirement. This mode of treatment is preferred when the facilities are available and the patients are willing for laparoscopy.

Maternal mortality secondary to ectopic pregnancy is totally avoidable with early diagnosis and better institutional management. We had zero mortality in our case series.

Availability of blood and blood products and ICU backup make management of ectopic and associated hemorrhagic shock an easy task and minimize the mortality. ${ }^{9}$ Five of our patients required ICU admission and management.

Medical management is an option in ectopic pregnancy provided they are diagnosed early. ${ }^{10}$

We managed three patients conservatively and two had successful outcome and one had to undergo laparotomy. Five observational studies have shown that 44 to $69 \%$ of pregnancies of unknown location resolve spontaneously with conservative management, ${ }^{6}$ which is comparable with this study. Conservative management is an option for clinically stable, asymptomatic patients with an ultrasound diagnosis of ectopic pregnancy and decreasing serum $\beta$-hCG, initially $<1000$ to $2000 \mathrm{mIU} / \mathrm{m}^{6}{ }^{6}$ Another seven observational studies were reviewed and a total of 478 patients were treated conservatively. Conservative management was successful in 318 (67\%) patients. Intervention has been shown to be required in 23 to $29 \%$ of cases. ${ }^{6}$

\section{CONCLUSION}

In the institutional setting, ectopic pregnancy accounted for $1.26 \%$ of total deliveries. In this study, $96 \%$ patients with ectopic pregnancy presented with the acute abdomen and required emergency laparotomy. About $10 \%$ patients could be managed with nonsurgical modalities with $66 \%$ success rate for methotrexate. The present study shows the important clinical aspects of ectopic pregnancy and its demographic variation in India. Early diagnosis and prompt conservative surgical or medical management will not only help in reducing maternal mortality and morbidity but also go a long way in preserving future fertility.

\section{REFERENCES}

1. Marion LL, Meeks GR. Ectopic pregnancy: history, incidence, epidemiology, and risk factors. Clin Obstet Gynaecol 2012 Jun;55(2):376-386.

2. Royal College of Obstetricians and Gynaecologists. The management of tubal pregnancy, Guideline No. 21. London: RCOG Press; 2010.

3. Braun RD. Surgical management of ectopic pregnancy. Online 2005. E- medicine. Available from: Available from: http:// www.emdeicin.com/med/topic3316.htm-94k [Last cited on 2011 Oct 20].

4. Sowter MC, Farquhar CM, Petrie KJ, Gudex G. A randomized trial of comparing single dose systemic methotrexate and laparoscopic surgery for the treatment of unruptured tubal pregnancy. Br J Obstet Gynecol 2001 Feb;108(2):192-203.

5. Grudzinskas JG. Miscarriage, ectopic pregnancy and trophoblastic disease. In: Edmonds DK. Dewhurst's textbook of obstetrics and gynaecology for postgraduates. 6th ed. Oxford: Blackwell Science 1999; 61-75.

6. The management of tubal pregnancy. Royal College of Obstetricians and Gynecologists Guidelines 2004 May; 21:1-10.

7. Van Mello NM, Mol F, Ankum WM, Mol BW, van der Veen F, Hajenius PJ. Ectopic pregnancy: how the diagnostic and therapeutic management has changed. Fertil Steril 2012 Nov;98(5):1066-1073.

8. Mahboob U, Mazhar SB. Management of ectopic pregnancy: a two-year study. Mother and Child Health Centre, Pakistan Institute of Medical Sciences, Islamabad, Pakistan.

9. Baxi A, Kaushal M, Karmalkar H, Sahu P, Kadhi P, Daval B. Successful expectant management of tubal heterotopic pregnancy. J Hum Reprod Sci 2010 May-Aug;3(2):108-110.

10. Ambarkar S, Baleswari G, Rajeswari P. Ectopic pregnancy: a clinical study in a Tertiary Institute. Journal of Evolution of Medical and Dental Sciences 2015 February;4(14):2326-2329. 